\title{
Giant bilateral adrenal lipoma in a patient with congenital adrenal hyperplasia
}

\author{
Tina Kienitz', Jörg Schwander¹, Ulrich Bogner1, Michael Schwabe², Thomas Steinmüller ${ }^{3}$ \\ and Marcus Quinkler ${ }^{1}$
}

1Endocrinology in Charlottenburg, Stuttgarter Platz 1, Berlin, Germany, 2Pathology, and 3Department of Abdominal and Endocrine Surgery, DRK-Kliniken Westend, Berlin, Germany
Correspondence should be addressed to M Quinkler

Email

marcusquinkler@t-online.de

\section{Summary}

Apart from adrenal myelolipomas, adrenal lipomatous tumors are rare and only seldom described in the literature. We present the case of a 50-year-old man, with a classical form of congenital adrenal hyperplasia (CAH), which was well treated with prednisolone and fludrocortisone. The patient presented with pollakisuria and shortness of breath while bending over. On MRI, fat-equivalent masses were found in the abdomen $(14 \times 19 \times 11 \mathrm{~cm}$ on the right side and $10 \times 11 \times$ $6 \mathrm{~cm}$ on the left side). The right adrenal mass was resected during open laparotomy and the pathohistological examination revealed the diagnosis of an adrenal lipoma. Symptoms were subdued totally postoperatively. This is the first report of a bilateral adrenal lipoma in a patient with CAH that we are aware of.

\section{Learning points:}

- Macronodular hyperplasia is common in patients with congenital adrenal hyperplasia (CAH).

- Solitary adrenal tumors appear in approximately $10 \%$ of adult CAH patients and are often benign myelolipomas.

- The Endocrine Society Clinical Practice Guideline does not recommend routine adrenal imaging in adult CAH patients.

- Adrenal imaging should be performed in CAH patients with clinical signs for an adrenal or abdominal mass.

- Adrenal lipoma is rare and histopathological examinations should rule out a differentiated liposarcoma.

\section{Background}

Myelolipoma is the most common type of adrenal lipomatous tumor. However, this is the only entity described in the group of adrenal lipomatous tumors in the 4th edition of World Health Organization (WHO) classification of tumors of endocrine organs (1), and other adrenal lipomatous tumors do not seem to be addressed. On CT imaging, myelolipomas are typically heterogeneous with low-density mature fat interspersed with more dense myeloid tissue. The classification depends on the relative proportion of fat and hematopoietic components. Myelolipomas are usually diagnosed between the $5^{\text {th }}$ and $7^{\text {th }}$ decade of life. The average size at diagnosis is $4-10 \mathrm{~cm}$ and mostly they are unilateral $(1,2)$. However, very large and bilateral tumors have been reported $(3,4,5,6,7)$. Myelolipomas are usually found incidentally, but sometimes symptoms appear, such as abdominal swelling and discomfort $(6,8)$, chronic back pain (7), or diffuse abdominal pain and vomiting (9) due to their size and pressure on the surrounding structures. Histologically, myelolipomas are composed of variable amounts of mature adipose tissue and scattered islands of haemopoietic elements, including erythroid, myeloid and lymphoid cell series as well as megakaryocytes (9). Hemorrhage and calcification may also be present.

The differential diagnoses of myelolipomas include other fat-containing adrenal masses, such as teratomas, lipomas and liposarcomas, angiomyolipomas, hibernomas, and fatty adrenal adenoma (1). 
A very rare differential diagnosis is a lipoma of the adrenal which can only be confirmed by the histological examination of the tumor mass as it contains no myeloid elements. In 2017, a review described all 24 reported cases of adrenal lipomas in the literature (1). Two-thirds of the reported cases originated in the Asian population seeming to be more frequent in men than in women. As with myelolipomas, lipomas are often detected around the $6^{\text {th }}$ decade of life. In $38 \%$ of the cases, symptoms (predominantly abdominal pain) lead to abdominal imaging and the diagnosis of the lipomas; $25 \%$ of the cases were detected at autopsy. Seventy-one percent of the adrenal lipomas were on the right side and the mean size was $75 \mathrm{~mm}(1)$.

To our knowledge, this is the first description of bilateral adrenal lipomas in a patient with congenital adrenal hyperplasia $(\mathrm{CAH})$.

\section{Case presentation}

A 50-year-old man who suffered from salt-wasting congenital adrenal hyperplasia (CAH) since his childhood was seen first in 1997 in our endocrine outpatient clinic and then regularly on a yearly basis (in 2019: weight 85 $\mathrm{kg}$, height $172 \mathrm{~cm}$, BMI $28.7 \mathrm{~kg} / \mathrm{m}^{2}$ ). The CAH was treated with prednisolone $5 \mathrm{mg}$ in the early morning and $2.5 \mathrm{mg}$ in the late evening in addition to fludrocortisone $0.1 \mathrm{mg}$ in the morning. Under this medication the patient never experienced an androgen precursor excess (17-hydroxyprogesterone levels were between 0.6 and $1.5 \mathrm{ng} / \mathrm{mL}$ (normal: $0.2-1.4 \mathrm{ng} / \mathrm{mL}$ ), androstenedione levels were between 0.24 and $0.5 \mathrm{ng} / \mathrm{mL}$ (normal: $0.5-3.5 \mathrm{ng} / \mathrm{mL}$ ), testosterone was between 1.7 and $2.1 \mathrm{ng} / \mathrm{mL}$ (normal: 1.3-7.7 $\mathrm{ng} / \mathrm{mL}$ ) and ACTH levels (16.7 and $37.5 \mathrm{pg} / \mathrm{mL}$ ) were within the normal range $(1.6-45 \mathrm{pg} / \mathrm{mL})$. Due to myocardial infarction at the age of 40 years (one-vessel coronary artery disease, treated by stent implantation) he additionally received metoprolol $47.5 \mathrm{mg}$ twice daily, simvastatin $20 \mathrm{mg}$ once daily, aspirin $100 \mathrm{mg}$ once daily and ramipril $1.25 \mathrm{mg}$ once daily. Since 2018, he has been experiencing increasing pollakisuria. Furthermore, he complained of shortness of breath while bending over to put on his shoes.

\section{Investigation}

On physical examination, the abdomen was soft and tender but with a palpable mass indistinguishable from the liver. An abdominal MRI scan (Fig. 1A and B) revealed fat-tissue equivalent masses in both adrenal regions with septic lobular appearance measuring $14 \times 19 \times 11 \mathrm{~cm}$ on the right side and $10 \times 11 \times 6 \mathrm{~cm}$ on the left side. The right kidney (displaying five cystic lesions up to $8.5 \mathrm{~cm}$ in diameter) and the renal artery were pushed into the lower right abdominal quadrant and the mass imprinted the liver, vena cava inferior and the pancreatic head. The left mass transposed the pancreas in ventral direction and the left kidney (with 7 parenchymal cysts up to $12 \mathrm{~mm}$ in diameter) into the lower left abdomen.

\section{Treatment}

The patient was scheduled for open laparotomy of the right mass (Fig. 2A) and several capsuled lipid tumors were removed (largest $200 \times 100 \times 100 \mathrm{~mm}$ weighing 1286 $\mathrm{g}$, and five additional specimens up to $120 \times 100 \times 40$
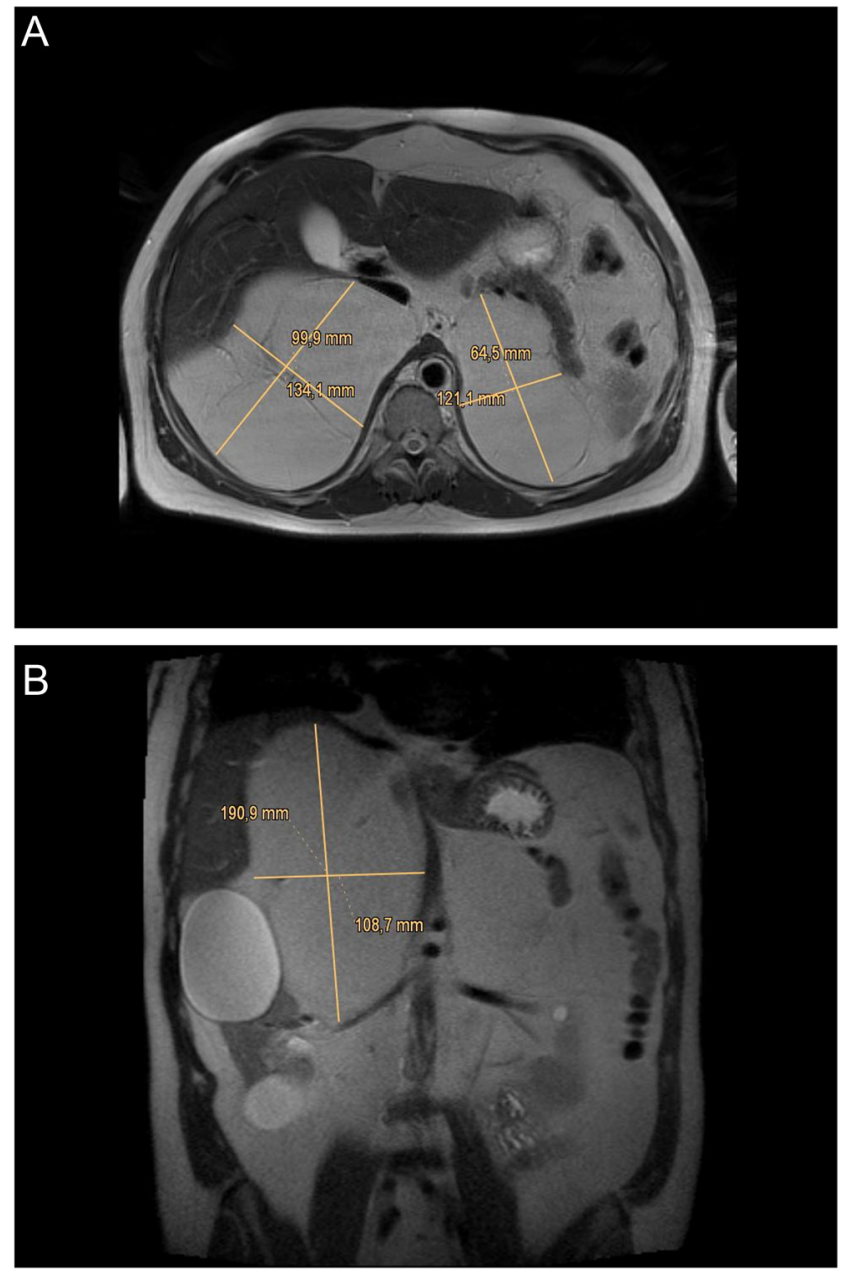

Figure 1

MRI axial (A) and coronar (B) scans (T2-weighted) showing fat-tissue equivalent masses in both adrenal regions with septic lobular appearance measuring $14 \times 19 \times 11 \mathrm{~cm}$ on the right side and $10 \times 11 \times 6 \mathrm{~cm}$ on the left side. 


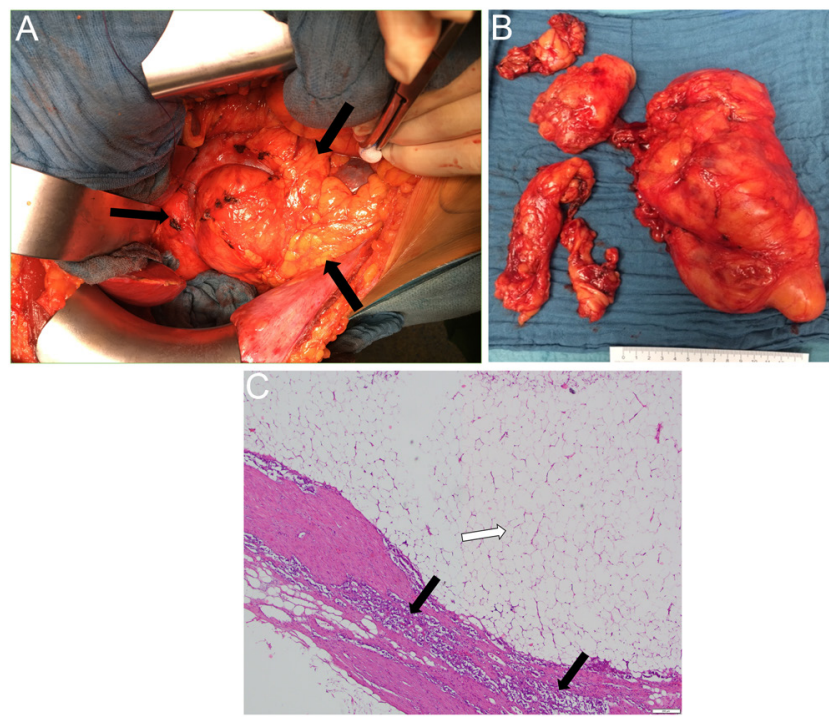

Figure 2

Intraoperative appearance of the situs (A) with capsuled lipid tumors (area between black arrows), removed right-sided tumors (B), and histopathology (hematoxylin and eosin staining) of right-sided adrenal lipoma showing $(C)$ a strip of connective tissue capsule with a small rim of typical trabecular adrenal cortex tissue (black arrows) and typical mature adipocytes (white arrow) (4× magnification).

$\mathrm{mm}$ in size) (Fig. 2B). Perioperatively, the patient received hydrocortisone $100 \mathrm{mg}$ i.v. as a bolus at the induction of anesthesia, postoperatively $100 \mathrm{mg}$ hydrocortisone i.v./24 $\mathrm{h}$ were administered until the second post-operative day when he was switched to oral hydrocortisone. The recovery was uneventful.

\section{Outcome and follow-up}

On histopathological examination the tumors consisted of univacuolaeric mature adipose tissue encapsulated by a fine connective tissue capsule (Fig. 2C). Adjacent to the capsule some typical trabecular adrenal tissue could be seen without signs of adrenal cortical hyperplasia. Due to the lack of any myeloid aspects, the diagnosis of adrenal lipoma was verified. No signs of malignancy were present and immunohistochemistry staining for MDM2 revealed no signs for a differentiated liposarcoma.

Pollakisuria stopped post-operatively and the abdominal discomfort vanished completely. The leftsided adrenal mass is being followed by regular MRI scans. Histological examination was only performed on the lesion removed from the right side. Therefore, we do not have definitive proof that the remaining lesion on the left side is a lipoma. However, this is highly probable based on its similar imaging appearance to the left-sided tumor.

\section{Discussion}

We report the first case of bilateral adrenal lipomas in a patient suffering from CAH. The Endocrine Society Clinical Practice Guideline (10) does not recommend routine adrenal imaging in adults with classical $\mathrm{CAH}$ due to 21-hydroxylase deficiency and this should be reserved for individuals with classic $\mathrm{CAH}$ who have clinical evidence of an adrenal or abdominal mass. This expert consensus derives from the fact that until now, only insufficient and contradictory data exist regarding routine screening for adrenal masses. One study using CT imaging in adults with $\mathrm{CAH}$ reported a high prevalence of benign adrenal masses (18 of 22 (83\%) CAH patients), especially among those on inadequate glucocorticoid (GC) therapy (11). However, the definition of an adrenal incidentaloma (tumor) in CAH may vary: If nodules in macronodular hyperplasia are counted as solitary tumors, the prevalence of adrenal incidentalomas will be high in CAH (12). Reisch et al. (13) reported adrenal nodules in 19 of 26 (73\%) patients with CAH. A systemic review that included 420 cases of adrenal myelolipoma showed that $10 \%$ of the cases were associated with CAH (12). A crosssectional population-based study in Norway revealed 9 adrenal tumors in 7 of 62 CAH patients $(11 \%)$ who routinely received adrenal CT imaging (2). The size of the tumors ranged from $12-165 \mathrm{~mm}$ in diameter; and four of the nine tumors were myelolipomas (diameter range: 33-58 mm) (12). The authors' conclusion was not to recommend routine adrenal imaging in $\mathrm{CAH}$ patients as not a single malignant adrenal tumor was found.

Chronic ACTH hyperstimulation is thought to be involved in the pathogenesis of myelolipomas of the adrenal and poor GC therapy compliance was found in some CAH cases (6), but not in others (7). In the cross-sectional population-based study in Norway, the authors did not find any difference in current GC or mineralocorticoid dose in $\mathrm{CAH}$ patients with or without adrenal tumors (12). In addition, CAH patients with adrenal tumors did not have significantly higher levels of 17-hydroxyprogesterone but higher ACTH levels than those without a tumor (12). The question arises, therefore, whether the melanocortin 2 receptor (MC2R) is at all expressed in myelolipomas. In a small study investigating four myelolipomas from four patients (two patients with $\mathrm{CAH}$, two without $\mathrm{CAH}$ ), the $M C 2 R$ gene was overexpressed in myelolipomas from three out of four patients (14). The study also investigated androgen receptor $(A R)$ overexpression which was detected in two tumors: a giant bilateral myelolipoma in a $\mathrm{CAH}$ 
patient and a sporadic case. However, the histological investigation failed to detect $M C 2 R$ overexpression in a myelolipoma in a CAH patient (4). Despite the clinical associations suggesting ACTH-mediated tumor growth, there are no consistent data to support the expression of $M C 2 R$ in myelolipomas.

The pathogenesis of adrenal lipomas has not been investigated so far. A recent study on soft tissue lipoma could not confirm the hypothesis that estrogen or progesterone receptors are involved in the pathogenesis of lipomas, but that angiogenesis might play a role in tumor growth (15). ACTH hypersecretion or androgen precursor excess was not present in our patient and could therefore be excluded as possible pathogenetic factors.

\section{Declaration of interest}

The authors declare that there is no conflict of interest that could be perceived as prejudicing the impartiality of the research reported.

\section{Funding}

This research did not receive any specific grant from any funding agency in the public, commercial or not-for-profit sector.

\section{Patient consent}

Written informed consent has been obtained from the patient for publication.

\section{Author contribution statement}

Tina Kienitz, Jörg Schwander, Ulrich Bogner and Marcus Quinkler treated the patient in their endocrine outpatient's clinic. Thomas Steinmüller operated the patient, Michael Schwabe performed the histological analysis. Marcus Quinkler planned the case report, coordinated the data collection and wrote the manuscript together with Tina Kienitz. All authors helped with the discussion.

\section{References}

1 Lam AK. Lipomatous tumours in adrenal gland: WHO updates and clinical implications. Endocrine-Related Cancer 201724 R65-R79. (https://doi.org/10.1530/ERC-16-0564)

2 Decmann Á, Perge P, Tóth M \& Igaz P. Adrenal myelolipoma: a comprehensive review. Endocrine 201859 7-15. (https://doi. org/10.1007/s12020-017-1473-4)

3 Mermejo LM, Elias Junior J, Saggioro FP, Tucci Junior S, Castro Md, Moreira AC \& Elias PC. Giant adrenal myelolipoma associated with 21-hydroxylase deficiency: unusual association mimicking an androgen-secreting adrenocortical carcinoma. Arquivos Brasileiros de Endocrinologia e Metabologia 201054 419-424. (https://doi. org/10.1590/s0004-27302010000400012)

4 Hagiwara H, Usui T, Kimura T, Tagami T, Naruse M, Minamiguchi S, Kato T, Okuno H \& Shimatsu A. Lack of ACTH and androgen receptor expression in a giant adrenal myelolipoma associated with 21-hydroxylase deficiency. Endocrine Pathology 200819 122-127. (https://doi.org/10.1007/s12022-008-9034-2)

5 German-Mena E, Zibari GB \& Levine SN. Adrenal myelolipomas in patients with congenital adrenal hyperplasia: review of the literature and a case report. Endocrine Practice 201117 441-447. (https://doi. org/10.4158/EP10340.RA)

6 McGeoch SC, Olson S, Krukowski ZH \& Bevan JS. Giant bilateral myelolipomas in a man with congenital adrenal hyperplasia. Journal of Clinical Endocrinology and Metabolism 201297 343-344. (https:// doi.org/10.1210/jc.2011-2373)

7 Kale G, Pelley EM \& Davis DB. Giant myelolipomas and inadvertent bilateral adrenalectomy in classic congenital adrenal hyperplasia. Endocrinology, Diabetes and Metabolism Case Reports 20152015 150079. (https://doi.org/10.1530/EDM-15-0079)

8 Akamatsu H, Koseki M, Nakaba H, Sunada S, Ito A, Teramoto S \& Miyata M. Giant adrenal myelolipoma: report of a case. Surgery Today 200434 283-285. (https://doi.org/10.1007/s00595-003-2682-4)

9 Ioannidis O, Papaemmanouil S, Chatzopoulos S, Paraskevas G, Konstantara A, Kotronis A, Kakoutis E \& Makrantonakis A. Giant bilateral symptomatic adrenal myelolipomas associated with congenital adrenal hyperplasia. Pathology Oncology Research 201117 775-778. (https://doi.org/10.1007/s12253-010-9330-2)

10 Speiser PW, Arlt W, Auchus RJ, Baskin LS, Conway GS, Merke DP, Meyer-Bahlburg HFL, Miller WL, Murad MH, Oberfield SE, et al. Congenital adrenal hyperplasia due to steroid 21-hydroxylase deficiency: an Endocrine Society clinical practice guideline. Journal of Clinical Endocrinology and Metabolism 2018103 4043-4088. (https:// doi.org/10.1210/jc.2018-01865)

11 Jaresch S, Kornely E, Kley HK \& Schlaghecke R. Adrenal incidentaloma and patients with homozygous or heterozygous congenital adrenal hyperplasia. Journal of Clinical Endocrinology and Metabolism 199274 685-689. (https://doi.org/10.1210/ jcem.74.3.1311000)

12 Nermoen I, Rørvik J, Holmedal SH, Hykkerud DL, Fougner KJ, Svartberg J, Husebye ES \& Løvås K. High frequency of adrenal myelolipomas and testicular adrenal rest tumours in adult Norwegian patients with classical congenital adrenal hyperplasia because of 21-hydroxylase deficiency. Clinical Endocrinology 201175 753-759. (https://doi.org/10.1111/j.1365-2265.2011.04151.x)

13 Reisch N, Scherr M, Flade L, Bidlingmaier M, Schwarz HP, MüllerLisse U, Reincke M, Quinkler M \& Beuschlein F. Total adrenal volume but not testicular adrenal rest tumor volume is associated with hormonal control in patients with 21-hydroxylase deficiency. Journal of Clinical Endocrinology and Metabolism 201095 2065-2072. (https:// doi.org/10.1210/jc.2009-1929)

14 Almeida MQ, Kaupert LC, Brito LP, Lerario AM, Mariani BM, Ribeiro M, Monte O, Denes FT, Mendonca BB \& Bachega TA. Increased expression of ACTH (MC2R) and androgen (AR) receptors in giant bilateral myelolipomas from patients with congenital adrenal hyperplasia. BMC Endocrine Disorders 2014 14 42. (https:// doi.org/10.1186/1472-6823-14-42)

15 Lee JB, Choi HJ, Son ET \& Kim JH. A research of soft tissue lipoma genesis factor with immunohistochemical analysis. Journal of Craniofacial Surgery 201728 871-876. (https://doi.org/10.1097/ SCS.0000000000003559) 